\title{
What is it to do good medical ethics? On the concepts of 'good' and 'goodness' in medical ethics
}

\author{
Jan Helge Solbakk
}

\section{Correspondence to} Dr Jan Helge Solbakk, Faculty of Medicine, Department of Health and Society, Centre for medical Ethics, University of Oslo, Box 1130, Blindern, Oslo 0318, Norway:

j.h.solbakk@medisin.uio.no

Received 30 July 2014 Revised 20 October 2014 Accepted 29 October 2014

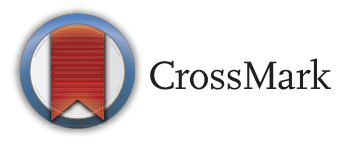

To cite: Solbakk JH. J Med Ethics 2015;41:12-16.

\section{ABSTRACT}

In his book The Varieties of Goodness Georg Henrik von Wright advocates that a useful preliminary to the study of the word 'good' is to compile a list of familiar uses and try to group them under some main headings. The present paper aims at exploring the question, 'What is it to do good medical ethics?', and notably from the vantage point of everyday expressions of the word 'good' and von Wright's grouping of them into six different types of goodness.

\section{INTRODUCTION}

In his book The Varieties of Goodness, ${ }^{1}$ Georg Henrik von Wright suggests that a useful preliminary to the study of the word 'good' is to compile a list of expressions from our everyday language and try to group them under some main headings. Here is a list of 30 such expressions, slightly different from the one introduced by von Wright: We talk of "a good knife", "a good car", "a good hammer", "a good road", "a good telephone", "a good carpenter", "a good chess player", "a good politician", "a good teacher", "a good lover/mistress", "a good lung", "good eyes", "good teeth", "good memory", "a good head", "a good heart", "a good smell", "a good meal", "a good wine", "a good opportunity", "good advice", "good luck", "good news", "a good man", "a good act".

In the following I invite readers to engage with me in a Socratic exploration of the question, "What is it to do good medical ethics?", taking inspiration from the list of everyday expressions here introduced.

(1) What is it to do good medical ethics? An instrumental answer.

The five first expressions contain uses of 'good' of an instrumental character; that is, we speak of a good knife, a good hammer, a good road as means for various purposes. So what could be an instrumental answer to the question above? In medical ethics, as in other scholarly disciplines, we need instruments in order to be able to do medical ethics, and do it in a good way. For example, medical ethics is in need of a normative languagethat is, a set of moral principles, or a full-fledged moral theory making us able to enlighten and research the moral terrain of medicine, to identify moral conflicts and, if possible, to resolve such conflicts in ways that are deemed morally consistent, coherent or acceptable by the different stakeholders affected.

Although the quest for theory has been a shared interest in medical ethics and medical epistemology for more than 40 years, there have been few attempts at addressing the question whether and eventually how and to what extent medical epistemology and medical ethics relate to each other. In spite of the admission that medical knowledge is a necessary condition for moral deliberations in medicine, there has been a tendency towards considering the question about the need for some larger theoretical framework in medical ethics as a question belonging to the pure realm of ethical theory, and by many to be the exclusive responsibility of ethicists. In medical epistemology, on the other hand, the quest for theory has seldom reflected any awareness of-or theoretical interest in-ethical issues. In his Introduction to the book, Moral Theory and Moral Judgements in Medical Ethics, ${ }^{2}$ Baruch Brody says that we must go beyond ethical principles if we are to find the appropriate epistemological foundations for medical ethics. Brody leaves, however, the reader in bewilderment, since he does not give any indications about how far beyond these principles he deems it necessary to go-and in what direction.

My claim is that what we-instrumentally speaking -need in order to do good medical ethics, is an action-oriented framework capable of rendering an account of the inter-relation between medical epistemology and medical ethics. Such a framework would be more fruitful than searching for a more refined moral theory, in order to solve the 'specification problem' and 'the theory-to-concrete-judgment-problem' which are common problems for all existing moral theories in medical ethics. ${ }^{2}$ Besides, such a framework would be able to handle two additional problems. First, the problem of identifying or assessing whether an issue dealt with in medical ethics actually is an ethical problem. That is, there are problems treated as 'ethical' problems, which are not ethical problems in the ordinary and pure sense of the word 'ethics', but problems related to a conflict between different conceptions of medical knowledge or between different interpretations of medical knowledge and empirical data. Second, there is the problem of moral residue, that is, the distressing experience of doubt, guilt, regret and remorse emerging from unresolved moral dilemmas which also is in need of treatment. ${ }^{3-5} \mathrm{~A}$ philosophical way of formulating this problem relates to a claim first made by Bernard Williams; the inability of ethical theories in their narratives of resolution of moral conflicts to account for the residual problem of remainder and regret. Moral conflicts, says Williams, are mainly of a contingent nature, that is, it is the world, not logic' that makes them occur. ${ }^{6}$ Dealing with moral conflicts therefore amounts to something 
more and perhaps different from simply doing away with logical inconsistencies.

(2) What is it to do good medical ethics? A technical answer.

A common characteristic of the members of the second group of 'goods' in the list above is that they are all good at something. That is, what the carpenter, the chess player, the politician, the teacher and the mistress all are good at, is some activity or art, for which they may possess a natural talent, but in which the person in possession will also have to undergo some training before he or she can excel in it. For the kind of goodness characteristic of this group von Wright suggests the label of technical goodness. ${ }^{1}$ What could then serve as a technically satisfactory answer to our question? Ethics teaching and learning might here serve as an example. To succeed in this endeavour I believe it is uncontroversial to say that technical goodness of some kind is required. But what exactly should ethics teachers be good at in order to succeed? How should teachers of medical ethics proceed didactically to make students benefit morally from their teaching and what should they aim at to achieve this? A standard set of answers to the second part of this question is that they should proceed in such a way as to raise moral awareness, foster moral reflection and self-reflection, increase moral understanding, enhance moral sensitivity and develop moral skills in their students. To these answers I suggest adding four metaphorical aims: to generate some kind of movement; to produce some sort of purification (catharsis); to foster therapeutic doubt; and finally, to reduce moral blindness. In alluding to metaphor here, I rely on Cynthia Ozick's claim that "metaphor is one of the chief agents of our moral nature"?

This raises then the question, What didactic approach is best suited to achieve these aims? One of the main ambitions in teaching medical ethics, I believe, is to make the students accept and understand that in non-ideal everyday situations it is seldom possible to reach a moral solution that is undoubtedly right, and that the real challenge consists rather in reaching an acceptable moral solution, that is, a solution that all parties involved find they can live with, all things considered. If this represents a true perception of the situation, then certainly it also becomes important to try to make the students aware of what a morally acceptable solution might look like. This leads to the question of what role ethical theories should play in the teaching sessions. In a textbook in medical ethics I coauthored some years ago, this issue is explicitly addressed. ${ }^{8}$ Seven different approaches in medical ethics are presented and discussed-a physician's ethics approach, principle-based ethics, utility-based ethics, duty-ethics, casuistry, virtue ethics and last, a common morality approach to medical ethics. The presentation is structured thus: after a short description of the position in question comes the confrontation with an authentic case. As the same test-case is used in relation to all positions presented, this gives the students the possibility of assessing the relative as well as the 'absolute' strengths and weaknesses of each position. In the presentation we try to demonstrate how each position can be used to defend diametrically opposed solutions. The intention behind this is partly to show that in moral decision making ethical theories can be used to reach theoretically consistent and coherent solutions. More important, however, is the intention to demonstrate that an ethical theory is only an instrument, and that depending on who is using the instrument-and the way it is used-the result might also differ. Thus, it becomes clear that it is not sufficient for a moral solution to be theoretically consistent and coherent; it must also be found to be morally acceptable by the different parties involved. This relates, first, to the simple fact that the logic of ethics is different from the logic of logic. Logical consistency and coherence are perhaps necessary but never sufficient conditions for achieving moral consistency and coherence. From this follows, second, that persuasion in ethical argumentation is of a more complex kind than in logic.

A metaphorical remark of Martha Craven Nussbaum may serve to emphasise this point: "To be fully successful as arguments, arguments must be such as to change the heart". 9 In my view, neither a theoretical nor a case-based approach is able to didactically achieve the kind of change here envisaged. In saying this, I do not question the didactic fruitfulness of employing medical case stories; they capture our imagination, they anchor moral reasoning in practice, they provide an account of lived experience and often point to possible ways of resolving moral dilemmas. ${ }^{10}$ In addition, ethicists need to test their ideas and theoretical frameworks, and notably by applying them to individual cases. ${ }^{11}$ What I question, however, is the perception that medical stories of sickness represent narratives that morally speaking are more authentic than so-called fictional cases. Medical case stories form a particular type of story-telling-a literary genre of its own, with its own distinct and defining features, hence also in need of being scrutinised by narrative theory. $^{12}$

In emphasising the moral contingency of case-based storytelling I rely on Aristotle's famous distinction in the Poetics between history and tragedy - the dominant form of moral narration in Greek antiquity. History, Aristotle says, narrates things that have happened, while tragedy relates to events or incidents that may happen. And this is, according to Aristotle, the reason why tragic poetry is more philosophical than history; it speaks of universals, whereas history is an account of particulars. ${ }^{13}$

These observations may serve to set the stage for an additional question of literary form, that is, the role of metaphor in ethics teaching. This brings us to Plato and his way of writing dialogues. According to Helmut Kuhn, Plato's intention behind creating the dialogue form was to make "a fresh start where the tragedians had left off" and "supplant their faulty tragedy with a poetry of his own, the truest tragedy". ${ }^{14}$ Space limitations preclude a detailed elaboration of the didactic assets and particularities of the dialogue form. For the sake of my argument it suffices to explore three metaphors Plato makes use of when talking about moral teaching and learning. First the metaphors of midwifery and pregnancy, introduced in the dialogue, Theaetetus: ${ }^{15}$

My art of midwifery is in general like theirs;..., and my concern is not with the body but with the soul that is in travail of birth. And the highest point of my art is the power to prove by every test whether the offspring of a young man's thought is a false phantom or instinct with life and truth.

These metaphors convey the message that moral learning is a vulnerable and risky business: in the same way as a woman's pregnancy can turn out to be a phantom pregnancy or lead to miscarriage or abortion so the process of moral learning might force a person to acknowledge that her/his own moral beliefs and convictions are unfounded, or ill-conceived and in need of being aborted. Second, they depict the process of teaching as something different from the provision of a certain amount of knowledge from a theoretical expert to an ignorant and passive receiver. As the midwife's task is not to give birth to a child of her own, but to use her art to assist and advise other women in the delivery, the ethics teacher's role in such a process is to be a 'helpful knower' in relation to the students' attempts at coming to terms with their own moral beliefs, convictions and doubts. Finally, as the midwives "can either bring on the pains of travail 
or allay them at their will, make a difficult labour easy, and at an early stage cause a miscarriage if they decide so", it is within the teacher's power and responsibility to deal in an artful way with pain and distress arising from the process of moral learning. ${ }^{16}$ While these metaphors are often recalled in the ethics literature, the third metaphor Plato makes use of is mainly neglected, that is, the metaphor of therapy and the allusion to some sort of purification (catharsis) necessary for moral learning: ${ }^{17}$

For as the physician considers that the body will receive no benefit from taking food until the internal obstacles have been removed, so the purifier of the soul is conscious that his patient will receive no benefit from the application of knowledge until he is refuted, and from refutation learns modesty; he must be purged of his prejudices first and made to think that he knows only what he knows, and no more.

When reading this quote in the context of ethics teaching and learning, four things should be kept in mind. For a first, the use of the physician-patient relationship to capture the relation between the ethics teacher and his/her students does not imply that the teacher should be thought of as the physician in this relationship. Second, the students should not be conceived of in analogy with a patient. Third, the only true physician in this relation is the dialogue going on between teacher and students. In other words, in a genuine dialogue about moral issues all parties involved become to some extent patients, since they all will undergo some sort of cathartic treatment. Fourth and last, but not the least, in such a relation the teacher may play the role of a drug-a pharmakon-in the students' attempt at coming to terms with their own morality.

Although there is a time span of more than 2300 years between the Socratic classroom staged in Plato's dialogues and our classrooms, I believe the (po)ethico-didactic insights displayed here are still worth keeping in mind for ethics teachers with the ambition of becoming really, really good at excelling in their art.

(3) What is it to do good medical ethics? A functional answer.

A third group of von Wright's uses of 'good' are when it describes organs of the body and faculties of the mind: for example, when we speak of a good heart, of good eyes, good sight, good memory. To these uses of 'good' he attributes the name of medical goodness. ${ }^{1}$ Functional goodness, I believe, is a more appropriate label, not least in a medical context, since medicine-as a discipline of research and as a practice-aims at generating understanding of and dealing with functional ailments causing disease and disease-induced forms of suffering. How then can the conception of functional goodness be of help in addressing the question of what it entails to do good medical ethics? That is, can we speak of neglected functional ailments of a normative kind in need of being rectified? The debate about exploitation and the question, "How to do research fairly in an unjust world" 18 may here serve as a disturbing example of dysfunctionality of a normative kind.

Since 1996, the global community of research policy makers, researchers and medical ethicists has been aware of the so-called 10/90 gap in medical and health-related research. This metaphor was introduced to depict the monstrous inequity in the world with respect to whose diseases are favoured in ongoing or planned research programmes. In concrete terms, this means that at least $90 \%$ of the economic resources spent annually on medical and health-related research target the health needs of the richest $10 \%$ of the world's population, while the needs of $90 \%$ of the world's population have to be met from the remaining $10 \%$ of research funding. ${ }^{19}$ Unfortunately, figures from recent empirical studies give reasons to claim that this gap has not diminished, although during the past 15 years the number of people from poor and low-income countries enrolled in clinical trials has substantially increased. ${ }^{20-22}$ This situation makes it justifiable to claim that international research today is carried out in a global climate of gross 'background injustice'; ${ }^{18}$ and that by the concerted action of powerful stakeholders in the affluent parts of the world, international research ethics is moving in a direction that contributes in itself to maintaining this injustice instead of reducing it.

With these observations in mind let us now turn to a formulation that for decades-albeit in slightly different versions-has been considered the normative bedrock of clinical research, that is, that the interests and welfare of the individual should have priority over the sole interest of science or society. ${ }^{23}$ During the last years several attempts have been made at diluting this commitment in international research ethics declarations and guidelines so as to comply better with the macro level interests of science and society.

The most influential of these attempts is the so-called fair benefit approach. ${ }^{24} 25$ At first reading this approach seems to be restricted to discussing procedures at the micro level of best achieving mutually advantageous forms of transactions between consenting and collaborative parties. The existing background injustice is taken as a fact of the world, implying that it "accepts the status quo in the host community as the appropriate 'normative baseline' against which proposed research initiatives" should be evaluated. ${ }^{26}$ This position profits directly from this background injustice by forcing poor communities and impoverished populations to enter into negotiations about the distribution of benefits in "situations of enormous inequality of bargaining power," 18 and with little likelihood of producing "outcomes that satisfy the minimal conditions of fairness that the proponents of this view themselves endorse". ${ }^{27}$ Negotiations in such a situation of enforced consent can hardly ever be said to comply with the requirements of appropriate consent procedures. The fair benefit approach, however, violates the requirements of informed consent; in addition, it gives legitimacy to the establishment of forms of collaboration that are clearly exploitative on the part of science of impoverished communities.

It is due time for concerned ethicists to join forces so as to heal the wounds that this turn has inflicted on the normative core commitments of international research. As argued by London and Zollman, ${ }^{27}$ for this to become true there is a need for grounding our duties in international research within a broader normative framework of social, distributive and rectificatory justice, that is, of moving the ethics focus from the micro level of informed consent and of quasi-consensual transaction procedures to a level of deliberation that includes as well issues of macro level distribution of basic goods and opportunities. Only then can we say that a well-functioning normative framework in international research ethics is in place, that is, a framework able to guide researchers in "how to do research fairly in an unjust world". ${ }^{18}$

(4) What is it to do good medical ethics? A beneficial answer.

The fourth type or form of goodness represented in the list above is beneficial goodness: ${ }^{1}$

Medicine is good for the sick, exercise for the health, manure for the soil, lubrication for the engine, to have good institutions is good for a country,... When we speak of a good plan, a good opportunity, good advice, good luck, good news, we are usually thinking of something which is useful or advantageous for some purpose or pursuit. 
An institutional answer to this question of relevance within the present context is the existence of well-functioning bioethics, clinical ethics and research ethics committees. The Universal Declaration on Bioethics and Human Rights advocates in Article 19 the establishment of independent, multidisciplinary and pluralist ethics committees at national, regional, local or institutional levels. ${ }^{23}$ In the majority of United Nations (UN) member states, such committees still do not exist, or their existence is just on paper. In view of the important role such ethics committees can play in assessing research protocols, in fostering public debate, awareness and engagement, and in promoting public policies, assisting countries and communities in such an endeavour should be high on the agenda of priorities of a medical ethics with the ambition of promoting beneficial goodness.

(5) What is it to do good medical ethics? A hedonic answer.

When we speak of a good smell, a good meal, a good wine, a good cigar, a good holiday or time, we have in mind the hedonic dimension of goodness. ${ }^{1}$ Viewing medicine from the vantage point of pain and pleasure, I believe it is justified to say that medicine is one of the most humane of disciplines, in the sense that it is continuously and relentlessly engaged in grappling with pain and disease-induced forms of suffering and in assisting patients in their desire to be cured and regaining their health. In spite of saying this, I believe more attention should be paid to the hedonic dimension of goodness, in medical research and in clinical practice, and consequently, in medical ethics. To first take the case of medical research; researchers live substantial parts of their lives in ambiences characterised by the freedom to seek knowledge, and characterised by tough competition, by temporary forms of insecurity and by ignorance. To make such ambiences flourish requires that attention is paid to the cognitive needs and aspirations of individual researchers, and to their need for being taken care of in periods of envy, frustration, insecurity and pain. Thus, coping with the pleasure of having a paper accepted for publication, a $\mathrm{PhD}$ dissertation accepted for defence or of receiving new funding in a way that acknowledges the contribution of one's helpers probably represents a less delicate matter than sharing the pains and responsibilities of a colleague who has failed in her aspirations to deliver according to the expectations of her peers. These all-to-human dimensions of doing research in a good way are seldom reflected in the ethics teaching curricula for prospective researchers.

Second, in the clinical ethics literature lots of attention is paid to forms of pain and suffering pertaining to tragic situations and to death and dying, while 'unspeakable situations' of pain, suffering and loss of capabilities and pleasure following survival of serious disease are hardly mentioned. One way of explaining this neglect is that these are problems of a different narrative fabric. While it is widely acknowledged that medicine is full of tragic situations, the 'unspeakable situations' of disease-induced pain and suffering are situations we feel embarrassed and ashamed to talk about and suffer from. To clarify this point, a return to Aristotle's Poetics might help. In the last part of this little book Aristotle introduces a definition of comedy, and notably in relation to his previous definition of tragedy: Tragedies, says Aristotle, dramatise irresolvable moral conflicts infected by some sort of failure (hamartia). ${ }^{13}$ A comedy, on the other hand, "dares to say the unsayable"; it deals with the unspeakable things in life, such as envy, frigidity and impotence, piss and shit, ugliness and other shameful things. ${ }^{28}$ These represent forms of pain and loss of pleasure that from the spectators' safe distance may evoke laughter and ridicule in them, not pity and fear, as is the case with tragic forms of suffering. But for the ailing patients these are dead serious things.
Men having undergone treatment for prostate cancer and women treated for breast cancer may here serve to illustrate the relevance of these forms of unspeakable suffering. Because of advances in early detection and treatment the numbers of prostate cancer and breast cancer survivors are steadily increasing. For these reasons more attention is needed towards the 'shameful' and unspeakable side effects of different forms of treatment and the possibilities of rehabilitation, especially problems pertaining to urinary, bowel and sexual functions and to changes in body image and self-esteem following surgery, chemotherapy, radiotherapy and hormone treatment. $^{29}$

In the medical ethics literature thousands of pages have been written about patients' rights to self-determination concerning decisions pertaining to health and disease. But what does it imply in practical terms to respect patients' idiosyncratic perceptions of their situation and the choices they make, and thereby their autonomy? Morally speaking this implies accepting that when we fall ill most of us shrink a bit compared with our normal selves, in the sense that our attention is more directed to our own fears and forms of suffering than to the needs of those near and dear to us, including for many patients problems of the unspeakable kind mentioned above. This is exactly the way Aristotle describes the moral horizon of the comic figure. If this represents a plausible perception of 'patientness', then it also becomes important to accept and respect the way patients might perceive and experience their situation, that is, not always in the way the predictable, judicially impeccable and rationally immaculate sort of person might react, but as a form of existence where the seemingly execrable and ridiculous dimensions of their lives occupy centre stage. For these reasons, medical ethics too needs to reorientate and widen its focus, so as not to exclude the seemingly comic dimensions of patients' sufferings from serious attention.

(6) What is it to do good medical ethics? A moral answer.

A last form of uses of 'good' proposed by von Wright, refers to matters of conduct and character, that is, uses of good related to the so-called moral life. The role of medical ethicists in the public sphere, that is, in public debate and in public policymaking, might serve as an example of what it morally entails to do good medical ethics. Since the time of Socrates the marketplace has been considered the original forum of public debate, dialogue and deliberation about ethically contentious issues. This historical fact, made known to us through the dialogues of Plato and the comic plays of Aristophanes, conveys the message that deliberation about such issues belongs to the public sphere; it is nurtured and promoted by taking place publicly, and notably between a variety of public in different fora open to them. In addition, it signals that nobody is the possessor of the ultimate moral truth. This is related to the fact that ethics represents a domain and a form of knowledge different from any expert knowledge, in the sense that everybody-and notably on equal terms-is entitled to partake in public debates, dialogues and deliberations about moral issues that might affect his or her life.

Before leaving the market-place of ancient Athens, a brief encounter with another influential public player of that age seems warranted; the Sophist movement, a philosophical strain of thought focusing on the argumentative potentials and power in the public sphere of artful speaking, that is, of rhetoric. According to Plato, their form of public discourse and debate was not aimed at promoting knowledge-based understanding and moral wisdom as was the case with Socrates's form of dialogue. On the contrary, by providing only those arguments that 
flattered and pleased their dialogue partners or confirmed their pre-existing moral perceptions, they aimed at generating manipulative forms of persuasion. When trying to determine the role of medical ethics in the public squares of today, the importance of this distinction between genuine dialogue and manipulative rhetoric cannot be overstated. An Editorial in the prestigious journal Nature some years ago might serve to illustrate this point: ${ }^{30}$

The professional field of bioethics has a great deal to say about many fascinating things, but people in this profession rarely say 'no'...Indeed, there is a tendency for career-conscious social scientists and humanists to become a little too cosy with researchers in science and engineering, telling them exactly what they want to hear.

A similar statement, but here in the form of a self-warning on behalf of the field of bioethics, reads as follows: ${ }^{31}$

The risk is that bioethics can be co-opted to justify (vs critically analyse) pre-existing scientific, and political positions, by finding the sympathetic individual and claiming she speaks for all bioethicists. We should be cognizant when speaking out not to open the door for others to use what we say and to ascribe to it the label of 'the' bioethics position. We should also guard against coercing consensus by declaring one vision of 'the good' based on the most powerful, most vocal, most Westernised, etc, argumentation.

In order for medical ethicists to be able to serve as genuine facilitators in public debate and policymaking, that is, to assist in promoting knowledge-based understanding and moral wisdom, I believe it is worthwhile paying serious attention to the critical remarks here made by Winner and Campbell.

\section{Competing interests None.}

Provenance and peer review Commissioned; internally peer reviewed.

\section{REFERENCES}

1 Von Wright GH. The varieties of goodness. London: Routledge \& Kegan Paul, 1963:8-12; 114-135.

2 Brody B, ed. Moral theory and moral judgements in medical ethics P\&M, 32. Dordrecht/Boston/London: Kluwer Academic Publishers, 1988:2.

3 McConnell T. Moral residue and dilemmas. In: Mason HE, ed. Moral dilemmas and moral theory. New York: OUP, 1996:36-47.

4 Greenspan PS. Practical guilt: moral dilemmas, emotions, and social norms. New York: OUP, 1995.

5 Webster G, Baylis F. Moral residue. In: Rubin SZ, Zoloth L, eds. Margin of error: the ethics of mistakes in the practice of medicine. Hagerstown: University Publishing Group, 2000:217-30.
6 Williams BAO. Ethical consistency. Proc Aristotelian Soc 1965;39:103-24.

7 Ozick C. Metaphor and memory. New York: Vintage International, 1989:270.

8 Ruyter KW, Førde R, Solbakk JH. Medisinsk etikk. En problembasert tilnærming (Medical ethics. A problem based approach). Oslo: Gyldendal Akademisk, 2000.

9 Nussbaum MC. The poetics of therapy: Hellenistic ethics in its rhetorical and literary context. Apeiron 1990;23(4):3.

10 Spranza M. The normative relevance of cases: rhetoric and empirical ethics. CQHCE 2012:21(4):481-92.

11 Chambers TS. The fiction of bioethics: a Précis. Am J Bioeth 2001;1(1):40-3.

12 Chambers TS. The fiction of bioethics: cases as literary texts. New York: Routledge, 1999.

13 Aristotle. Poetics 51b8-12. In: Janko R, ed.. Poetics / with Tractatus Coislinianus. A Hypothetical Reconstruction of Poetics II. The Fragments of the On Poets. Indianapolis/Cambridge: Hackett Publishing Company, 1987.

14 Kuhn H. The true tragedy: On the relationship beteween Greek tragedy and Plato. HSCP 1941;52:1-2.

15 Plato. Theaetetus, 150b5-10. In: Hamilton E, Cairns H, eds, The collected dialogues of Plato, including the letters: Bollingen Series LXXI. Princeton, New Jersey: Princeton University Press, 1989.

16 Plato. Theatetus, 149c9-d3, 151a7-b1.

17 Plato. Sophist, 230c3-d3.

18 Ballantyne A. How to do research fairly in an unjust world. Am J Bioeth 2010;10:26-35

19 Ad Hoc Committee on Health Research Relating to Future Intervention Options. Investing in Health Research and Development. Geneva: World Health Organization, 1996.

20 Petryna A. Clinical trials offshored: On private sector science and public health. BioSocieties 2007:2:21-40.

21 Thiers FA, Sinskey AJ, Berndt ER. Trends in the globalization of clinical trials. Nat Rev Drug Discov 2008;7:13-4.

22 Glickman SW, McHutchison JG, Peterson ED, et al. Ethical and scientific implications of the globalization of clinical research. N Engl J Med 2009;360: 816-23.

23 Universal Declaration on Bioethics and Human Rights, Article 3.2, 2005. http:/l portal.unesco.org/shs/en/ev.phpURL_ID1/41883\&URL_D01/4DO_TOPIC\&URL SECTION1/4201.html (accessed 24 Jul 2014).

24 Participants in the 2001 Conference on Ethical Aspects of Research in Developing Countries. Ethics: fair benefits for research in developing countries. Science 2002:298:2133-4.

25 Millum J, Wendler D, Emanuel E. The 50th anniversary of the Declaration of Helsinki: progress but many remaining challenges. JAMA 2013:310(20):2143-4.

26 London AJ. Justice and the human development approach to international research. Hastings Cent Rep 2005:35:24-37.

27 London AJ, Zollman KJS. Research at the auction block. Problems for the fair benefit approach to international research. Hastings Cent Rep 2010;40:34-45.

28 Segal E. The death of comedy. Massachusetts: Harvard University Press, 2001:31.

29 Rasmusson E-M, Plantin L, Elmerstig E. 'Did they think I would understand all that on my own?' A questionnaire study about sexuality with Swedish cancer patients. Eur J Cancer Care (Engl) 2013:22:361-9.

30 [No authors listed]. Bioethics at the bench. Nature 2006;440:1089-90.

31 Campbell AT. Bioethics in the public square: reflections on the how. J Med Ethics 2013:39(3):130-4. 